\title{
AVALIAÇÃO DOS OBJETIVOS SOBRE SAÚDE DOS PARÂMETROS CURRICULARES NACIONAIS POR PROFESSORES MUNICIPAIS DE SÃO LEOPOLDO, RS.
}

\author{
Carolina Estrada ${ }^{1}$, José Cláudio Del Pino ${ }^{2}$ \\ ${ }^{1}$ Universidade Federal do Rio Grande do Sul, mestranda no PPG Educação em Ciências, \\ ctsestrada@yahoo.com.br. \\ ${ }^{2}$ Universidade Federal do Rio Grande do Sul, Área de Educação Química, professor do PPG Educação \\ em Ciências, delpinojc@yahoo.com.br.
}

\begin{abstract}
Resumo
A prevenção é o foco da educação no que diz respeito aos conceitos envolvendo a saúde do educando. Vendo a escola como uma contribuinte e negando seu papel determinista na formação do sujeito, como a escola pode auxiliar na manutenção da Saúde? O que o professor enxerga como necessário à aprendizagem do aluno dentro dessa temática? No ano de 2008, os professores atuantes dos anos iniciais do Ensino Fundamental da Rede Municipal de Ensino do Município de São Leopoldo receberam um questionário solicitando a qualificação dos objetivos determinados pelos PCN's para a área Saúde. Trezentos e quarenta e três professores atuantes nos anos iniciais do Ensino Fundamental da Rede Municipal de Educação de São Leopoldo responderam à questão proposta. Os professores generalistas avaliaram os objetivos como relevantes, justificando o desenvolvimento dos mesmos com seus alunos. Tendo a educação como fator permanente na vida do sujeito, a escola é um elemento que influencia essa formação. Não podendo ser vista como uma instituição que determina pensamentos. Promover Saúde se mostra um compromisso assumido pelos professores, mas não garante que a conduta do indivíduo será como o "ensinado" na escola. O sujeito faz suas escolhas, o sujeito compreende a seu modo o objeto.
\end{abstract}

Palavras-chave: anos iniciais do Ensino Fundamental, Saúde, trabalho docente.

\section{Saúde e Educação}

A prevenção é o foco da educação no que diz respeito aos conceitos envolvendo a saúde do educando. Tones (1987) diz que prevenir a doença por meio da modificação do comportamento, desenvolvendo novos comportamentos saudáveis e mudando as práticas insanas existentes é um fator a contribuir ao bem estar do indivíduo.

A Organização Mundial da Saúde (1986) esclarece que a saúde é o maior influenciador para o desenvolvimento social, econômico e pessoal, determinando a qualidade de vida. Recomenda também que as premissas para a saúde são: paz, educação, habitação, alimentação, renda, ecossistema estável, recursos sustentáveis, justiça social e eqüidade, insinuando que um ser integralmente satisfeito de suas 
necessidades físicas e psicológicas é aquele que possivelmente possuirá uma boa saúde. O que a educação pode influenciar?

Aqui nos deparamos no contínuo ciclo que existe entre o fazer e o compreender. Como explica Piaget (1978): “fazer é compreender em ação uma dada situação em grau suficiente para atingir os fins propostos, e compreender é conseguir dominar, em pensamento, as mesmas situações até poder resolver os problemas por elas levantados, em relação ao porquê e ao como das ligações constatadas e, por outro lado, utilizadas na ação" (pg.176). Como contribuir para que o sujeito compreenda algo? Elias \& Feldmann (1993) aconselham o professor a construir coletivamente o saber, ao permitir a busca do novo, o risco, a descoberta, o diálogo, a troca, o conhecer, deixando que cada educando assuma a sua própria prática dentro dos seus limites.

Segundo Morais (1992), o ser humano é possuidor de desejos e não de necessidades. Muitos dos nossos comportamentos são explicados pelo desejo que se expressa de diversas formas. Atualmente, boa parte dos seres humanos está com suas necessidades fisiológicas satisfeitas, há disponibilidade. Aí, abre-se espaço para o desejo. Exemplificando, Justus (1999) indica que no ato da nutrição o homem biológico e o social são confundidos. Na primitiva necessidade da alimentação, passamos a uma época que não só o fisiológico determina o que e quando comer, mas o ser social influencia fortemente nessas decisões.

Carvalho (1997) lembra que no movimento educacional dos anos 20, a saúde é um dos focos da campanha de regeneração nacional pela educação. A educação como salvação está entranhada na história da educação. Uma escola "milagreira" é apontada por Angelis (1997) quando diz que o saneamento, a profilaxia, a higiene não são elementos suficientes de combate. É preciso a educação, como o maior recurso para os milagres da regeneração física.

Vendo a escola como uma contribuinte e negando seu papel determinista na formação do sujeito, como a escola pode auxiliar na manutenção da Saúde? O que o professor enxerga como necessário à aprendizagem do aluno nessa temática?

\section{Perguntando aos professores}

No ano de 2008, os professores atuantes dos anos iniciais do Ensino Fundamental da Rede Municipal de Educação do município de São Leopoldo receberam um questionário com a seguinte questão: 
Quanto aos conteúdos nas aulas de Ciências, qualifique os objetivos abaixo de acordo com a sua importância de abordagem na sua turma. Utilize a legenda a seguir:

1- Objetivo sempre almejado, de grande relevância.

2- Objetivo ambicionado se houver tempo ou interesse dos alunos, de média relevância.

3- Objetivo não almejado, sem importância dentro do ano letivo atual.

1.( ) Expressar suas necessidades de atenção à Saúde.

2.( ) Responsabilizar-se com crescente autonomia por sua higiene corporal, percebendo-a como fator de bem-estar e como valor da convivência social.

3. ( ) Conhecer e desenvolver hábitos alimentares favoráveis ao crescimento e ao desenvolvimento.

4.( ) Conhecer e evitar os principais riscos de acidentes no ambiente doméstico, na escola e em outros lugares públicos.

5.( ) Conhecer e utilizar medidas de primeiros socorros ao seu alcance.

6.( ) Reconhecer as doenças transmissíveis mais comuns em sua região.

7. ( ) Conhecer os recursos de saúde disponíveis e necessários para a saúde da comunidade.

8.( ) Outros. Especifique:

Trezentos e quarenta e três professores atuantes nos anos iniciais do Ensino Fundamental da Rede Municipal de Educação de São Leopoldo responderam a questão proposta.

\section{Relevâncias dos objetivos}

Um dos objetivos citados pelos Parâmetros Curriculares Nacionais para a temática Saúde nos primeiros anos do Ensino Fundamental é o de expressar suas necessidades de atenção à Saúde. Um objetivo que pretende que o aluno seja capaz de perceber, discernir e comunicar sensações de desconforto ou dor, sabendo localizá-las em seu corpo e buscando ajuda quando necessário (Brasil, 1997).

Expressar suas necessidades de atenção à Saúde é um objetivo de grande relevância para 89,50\% dos professores generalistas da Rede Municipal de Ensino de São Leopoldo. Avaliando-o como de média relevância são 5,54\% dos profissionais questionados pela pesquisa. Este objetivo é irrelevante para 2,62\% dos docentes (Figura 1 e Tabela 1). 
Tabela 1: Número e porcentagem de professores distribuídos conforme sua avaliação nas diferentes categorias de relevância do objetivo 1 do bloco Saúde integrante dos Parâmetros Curriculares

Nacionais.

\begin{tabular}{|l|l|l|}
\hline Expressar suas necessidades de atenção à Saúde. & Número de professores & \% \\
\hline Grande relevância & 307 & 89,50 \\
\hline Média relevância & 19 & 5,54 \\
\hline Sem relevância & 9 & 2,62 \\
\hline Não respondeu & 8 & 2,33 \\
\hline
\end{tabular}

Responsabilizar-se com crescente autonomia por sua higiene corporal, percebendo a como fator de bem-estar e como valor da convivência social é um objetivo que visa que o aluno seja capaz de executar ações de higiene corporal de maneira autônoma e reconhecer a importância de sua realização cotidiana. Incluem-se entre as ações básicas: lavar as mãos antes das refeições e após o uso do banheiro, tomar banho diário, cuidar de cabelos e unhas, escovar os dentes após as refeições e utilizar adequadamente o sanitário (Brasil, 1997).

O objetivo responsabilizar-se com crescente autonomia por sua higiene corporal, percebendo a como fator de bem-estar e como valor da convivência social é qualificado como detentor de grande relevância no trabalho com os anos iniciais do Ensino Fundamental para 91,55\% dos professores, de média relevância para 4,96\% dos profissionais questionados e apresenta-se sem qualquer relevância para 1,17\% dos docentes Figura 1 e Tabela 2).

Tabela 2: Número e porcentagem de professores distribuídos conforme sua avaliação nas diferentes categorias de relevância do objetivo 2 do bloco Saúde integrante dos Parâmetros Curriculares

Nacionais.

\begin{tabular}{|l|l|l|}
\hline $\begin{array}{l}\text { Responsabilizar-se com crescente autonomia por sua higiene } \\
\text { corporal, percebendo-a como fator de bem-estar e como valor da } \\
\text { convivência social. }\end{array}$ & $\begin{array}{l}\text { Número de } \\
\text { professores }\end{array}$ & $\%$ \\
\hline Grande relevância & 314 & 91,55 \\
\hline Média relevância & 17 & 4,96 \\
\hline Sem relevância & 4 & 1,17 \\
\hline Não respondeu & 8 & 2,33 \\
\hline
\end{tabular}

Outro objetivo avaliado pelos professores generalistas da Rede Municipal de Educação de São Leopoldo foi o de conhecer e desenvolver hábitos alimentares favoráveis ao crescimento e ao desenvolvimento. Obtendo sucesso no desenvolvimento do mesmo, o aluno será capaz de descrever as necessidades nutricionais básicas do organismo humano, indicando os alimentos adequados para a composição de um 
cardápio nutritivo utilizando os recursos e a cultura alimentares de sua região (Brasil, 1997).

Conhecer e desenvolver hábitos alimentares favoráveis ao crescimento e ao desenvolvimento é de grande relevância para $87,17 \%$ dos docentes questionados pela pesquisa, 9,33\% destes acreditam que o objetivo tem média relevância no seu trabalho com os primeiros anos do Ensino Fundamental. Irrelevante é este objetivo para 1,46\% dos docentes (Figura 1 e Tabela 3).

Tabela 3: Número e porcentagem de professores distribuídos conforme sua avaliação nas diferentes categorias de relevância do objetivo 3 do bloco Saúde integrante dos Parâmetros Curriculares

Nacionais.

\begin{tabular}{|l|l|l|}
\hline $\begin{array}{l}\text { Conhecer e desenvolver hábitos alimentares favoráveis ao } \\
\text { crescimento e ao desenvolvimento. }\end{array}$ & $\begin{array}{l}\text { Número de } \\
\text { professores }\end{array}$ & $\%$ \\
\hline Grande relevância & 299 & 87,17 \\
\hline Média relevância & 32 & 9,33 \\
\hline Sem relevância & 5 & 1,46 \\
\hline Não respondeu & 7 & 2,04 \\
\hline
\end{tabular}

Com o objetivo de conhecer e evitar os principais riscos de acidentes no ambiente doméstico, na escola e em outros lugares públicos, espera-se que o aluno seja capaz de identificar e evitar os principais riscos de acidentes, de valorar adequadamente as situações de risco à integridade e à saúde pessoais e de terceiros (Brasil, 1997).

Conhecer e evitar os principais riscos de acidentes no ambiente doméstico, na escola e em outros lugares públicos é de grande relevância para 69,10\% dos docentes questionados, de média relevância para $20,12 \%$ dos professores e irrelevante no seu trabalho com os anos iniciais do Ensino Fundamental para 8,16\% dos profissionais (Figura 1 e Tabela 4).

Tabela 4: Número e porcentagem de professores distribuídos conforme sua avaliação nas diferentes categorias de relevância do objetivo 4 do bloco Saúde integrante dos Parâmetros Curriculares Nacionais.

\begin{tabular}{|l|l|l|}
\hline $\begin{array}{l}\text { Conhecer e evitar os principais riscos de acidentes no ambiente } \\
\text { doméstico, na escola e em outros lugares públicos. }\end{array}$ & $\begin{array}{l}\text { Número de } \\
\text { professores }\end{array}$ & $\%$ \\
\hline Grande relevância & 237 & 69,10 \\
\hline Média relevância & 69 & 20,12 \\
\hline Sem relevância & 28 & 8,16 \\
\hline Não respondeu & 9 & 2,62 \\
\hline
\end{tabular}


Desenvolvendo o objetivo de conhecer e utilizar medidas de primeiros socorros ao seu alcance, acredita-se que o aluno realize procedimentos básicos de primeiros socorros em caso de pequenos acidentes. Incluem-se: a higienização de ferimentos superficiais, o uso de compressas frias em caso de contusões, o controle de perda de sangue pelo nariz, etc. O educando deve discernir problemas de maior gravidade, reconhecendo a necessidade de buscar auxílio de adultos e/ou profissionais de saúde (Brasil, 1997).

Conhecer e utilizar medidas de primeiros socorros ao seu alcance é uma meta de grande relevância para 43,44\% dos professores que trabalham com alunos dos primeiros anos do Ensino Fundamental. É um objetivo avaliado como de média relevância para 33,53\% dos profissionais em questão. Irrelevante é o mesmo para 20,70\% dos docentes (Figura 1 e Tabela 5).

Tabela 5: Número e porcentagem de professores distribuídos conforme sua avaliação nas diferentes categorias de relevância do objetivo 5 do bloco Saúde integrante dos Parâmetros Curriculares Nacionais.

\begin{tabular}{|l|l|l|}
\hline $\begin{array}{l}\text { Conhecer e utilizar medidas de primeiros socorros ao seu } \\
\text { alcance. }\end{array}$ & $\begin{array}{l}\text { Número } \\
\text { professores }\end{array}$ & de \\
\hline Grande relevância & 149 & 43,44 \\
\hline Média relevância & 115 & 33,53 \\
\hline Sem relevância & 71 & 20,70 \\
\hline Não respondeu & 8 & 2,33 \\
\hline
\end{tabular}

Outro objetivo qualificado pelos docentes generalistas atuantes nas escolas municipais de São Leopoldo foi: reconhecer as doenças transmissíveis mais comuns em sua região. Com ele, espera-se que o aluno seja capaz de reconhecer as doenças transmissíveis mais comuns em seu meio, identificando as condições sanitárias associadas à sua ocorrência, as formas de contágio e prevenção, assim como os sinais, sintomas e cuidados básicos para a cura (Brasil, 1997).

Reconhecer as doenças transmissíveis mais comuns em sua região é um objetivo de grande relevância para 52,19\% dos professores questionados. Para 30,90\% dos docentes, este é um objetivo de média relevância. Irrelevante se faz este objetivo para $14,58 \%$ dos profissionais participantes desta pesquisa (Figura 1 e Tabela 6).

Tabela 6: Número e porcentagem de professores distribuídos conforme sua avaliação nas diferentes categorias de relevância do objetivo 6 do bloco Saúde integrante dos Parâmetros Curriculares

Nacionais. 


\begin{tabular}{|l|l|l|}
\hline $\begin{array}{l}\text { Reconhecer as doenças transmissíveis mais comuns em sua } \\
\text { região. }\end{array}$ & $\begin{array}{l}\text { Número } \\
\text { professores }\end{array}$ & de \\
\hline Grande relevância & 179 & 52,19 \\
\hline Média relevância & 106 & 30,90 \\
\hline Sem relevância & 50 & 14,58 \\
\hline Não respondeu & 8 & 2,33 \\
\hline
\end{tabular}

Com o objetivo de conhecer os recursos de saúde disponíveis e necessários para a saúde da comunidade, deseja-se que o aluno demonstre conhecimento crítico a respeito da função dos diferentes serviços de saúde, assim como das formas de acesso aos serviços existentes na região em que vive (Brasil, 1997).

Conhecer os recursos de saúde disponíveis e necessários para a saúde da comunidade é de grande relevância para $51,60 \%$ dos professores. Avaliado como de média relevância foi para $31,49 \%$ dos profissionais e se faz irrelevante para 13,99\% dos docentes (Figura 1 e Tabela 7).

Tabela 7: Número e porcentagem de professores distribuídos conforme sua avaliação nas diferentes categorias de relevância do objetivo 7 do bloco Saúde integrante dos Parâmetros Curriculares Nacionais.

\begin{tabular}{|l|l|l|}
\hline $\begin{array}{l}\text { Conhecer os recursos de saúde disponíveis e } \\
\text { necessários para a saúde da comunidade. }\end{array}$ & Numero de professores & $\%$ \\
\hline Grande relevância & 177 & 51,60 \\
\hline Média relevância & 108 & 31,49 \\
\hline Sem relevância & 48 & 13,99 \\
\hline Não respondeu & 10 & 2,92 \\
\hline
\end{tabular}

\section{Saúde e o trabalho docente}

A Figura 1 e Tabela 8 mostram a grande relevância da temática Saúde dentro do trabalho dos professores generalistas da Rede Municipal de Educação de São Leopoldo. 


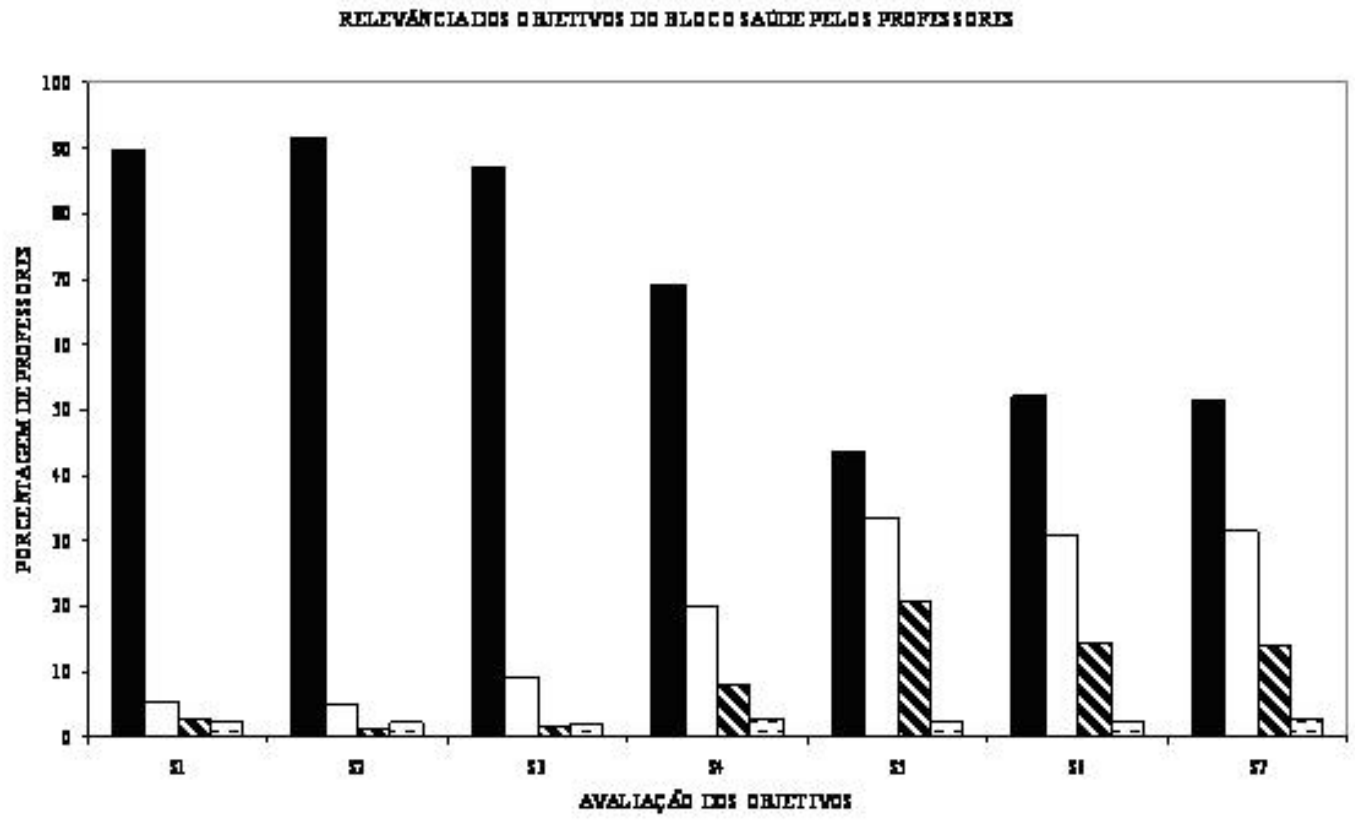

Figura 1: Reunião dos 7 objetivos do bloco Saúde o qual integra os Parâmetros Curriculares Nacionais com a avaliação da relevância dos objetivos pelos professores da Rede Municipal de Ensino de São Leopoldo atuantes nos primeiros anos do Ensino Fundamental. A barra preta indica a grande relevância do objetivo segundo os professores. A barra branca indica a média relevância do objetivo pela opinião dos professores. A barra preta com listas diagonais brancas indica a não relevância do objetivo de acordo com os docentes. A barra branca tracejada indica a porcentagem de professores que não respondeu a questão. S1. Expressar suas necessidades de atenção à Saúde.

S2. Responsabilizar-se com crescente autonomia por sua higiene corporal, percebendo-a como fator de bem-estar e como valor da convivência social. S3. Conhecer e desenvolver hábitos alimentares favoráveis ao crescimento e ao desenvolvimento. S4. Conhecer e evitar os principais riscos de acidentes no ambiente doméstico, na escola e em outros lugares públicos. S5. Conhecer e utilizar medidas de primeiros socorros ao seu alcance. S6. Reconhecer as doenças transmissíveis mais comuns em sua região. S7. Conhecer os recursos de saúde disponíveis e necessários para a saúde da comunidade.

A Figura 1 e a Tabela 8 deixam clara a importância que o professor vê nos objetivos da temática Saúde. Assuntos que não demandam especiais conhecimentos, onde impera a reprodução do senso comum, são preferidos, como os conteúdos referentes à alimentação e higiene. 
Tabela 8: Porcentagem de professores nas avaliações dos 7 objetivos do bloco Saúde nas diferentes categorias de relevância.

\begin{tabular}{|l|l|l|l|l|l|l|l|}
\hline OBJETIVO & S1 & S2 & S3 & S4 & S5 & S6 & S7 \\
\hline Grande relevância & 89,50 & 91,55 & 87,17 & 69,10 & 43,44 & 52,19 & 51,60 \\
\hline Média relevância & 5,54 & 4,96 & 9,33 & 20,12 & 33,53 & 30,90 & 31,49 \\
\hline Sem relevância & 2,62 & 1,17 & 1,46 & 8,16 & 20,70 & 14,58 & 13,99 \\
\hline Não respondeu & 2,33 & 2,33 & 2,04 & 2,62 & 2,33 & 2,33 & 2,92 \\
\hline
\end{tabular}

\section{Especificando...}

Os professores especificaram os seguintes assuntos importantes a serem trabalhados nas suas aulas de Ciências nos primeiros anos do Ensino Fundamental: alimentação saudável e qualidade de vida.

\section{Pensando as qualificações...}

Diz Paulo Freire (2003) que "é na inconclusão do ser, que se sabe como tal, que se funda a educação como processo permanente. Mulheres e homens se tornaram educáveis na medida em que se reconheceram inacabados. Não foi a educação que fez mulheres e homens educáveis, mas a consciência de sua inconclusão é que gerou sua educabilidade. É também na inconclusão de que nos tornamos conscientes e que nos inserta no movimento permanente de procura que se alicerça a esperança" (p.58). Portanto, tendo a educação como fator permanente na vida do sujeito, a escola é um elemento que influencia essa formação. Não pode ser vista como uma instituição que determina pensamentos.

Para Calamé (1995), é preciso arquitetar um humanismo para o século XXI que não desmembre o sentido do saber, que elucide que a criatividade nasce de onde não é aguardada, da união de conceitos e de opiniões variadas; que não dissocie o corpo da mente; que respeitem os homens mais que o conjunto de seus órgãos, as unidades culturais mais do que a coleção de seus elementos.

Freud (1996:271) elucida que "a medicina fez seus maiores progressos tanto na qualidade de ciência como na de arte: desvendou a composição do organismo a partir de unidades microscopicamente pequenas (as células), aprendeu a compreender física e quimicamente cada um dos processos (funções vitais), distinguiu as modificações visáveis e palpáveis das partes do corpo em consequiência dos diferentes processos patológicos, e descobriu por outro lado, os indícios pelos quais se revelam os processos patológicos entranhados a fundo no organismo vivo; desvendou ainda um grande número dos micróbios patogênicos e, com a ajuda dos conhecimentos recém adquiridos, 
reduziu extraordinariamente os perigos das intervenções cirúrgicas mais graves”. De nada vale uma medicina altamente eficaz se os indivíduos não compreendem e não agem a favor da sua saúde pessoal. Aí entra o trabalho singular da educação. Fazer com que os alunos conheçam os hábitos que promovem a sua saúde parece ser uma tarefa que o professor se incumbe.

Conhecendo o ser humano integralmente, possibilita maior precisão das suas necessidades e desejos. Promover Saúde se mostra um compromisso assumido pelos professores, mas não garante que a conduta do indivíduo será como o "ensinado" na escola. O sujeito faz suas escolha, ninguém pode fazer o outro compreender, o sujeito compreende a seu modo o objeto. Esse poder, o professor não tem.

\section{REFERÊNCIAS BIBLIOGRÁFICAS}

Angelis, Nicolau Meira. Pela perfeição da raça brasileira. In: Costa, Maria José Franco Ferreira et alii (org.). I Conferência Nacional de Educação: Curitiba, 1927. Brasília: MEC/IPARDES, 1997. 437-445.

Brasil. Ministério da Educação e do Desporto. Parâmetros Curriculares Nacionais, Primeiro e Segundo Ciclos do Ensino Fundamental - Saúde. Brasília, 1997. Calame, Patrick. Defesa de uma redistribuição de saberes. In: Witkowski, Nicolas. Ciência e tecnologia hoje. São Paulo: Ensaio, 1995. 176-178.

Carvalho, Marta Maria Chagas. Quando a história da educação é a história da disciplina e da higienização das pessoas. In: Freitas, Marco Cezar (org.). História Social da Infância no Brasil. São Paulo: Cortez, 1997. 269-287.

Elias, Marisa del Cioppo \& Feldmann, Marina Graziela. A busca da interdisciplinaridade e competência nas disciplinas dos cursos de Pedagogia. In: Fazenda, Ivani Catarina Arantes. (org) Práticas Interdisciplinares na Escola. São Paulo: Cortez, 1993. 91-102.

Freire, Paulo. Pedagogia da Autonomia: saberes necessários à prática educativa. São Paulo: Paz e Terra, 2003.

Freud, Sigmund. Três ensaios sobre a teoria da sexualidade e outros trabalhos. (1905). In: Freud, Sigmund. Edição Standard brasileira das obras psicológicas completas de Sigmund Freud. v. VII. Rio de Janeiro: Imago, 1996. 117-231. Justus, Daisy. Por uma psicopatologia da alimentação cotidiana. In: Encontro Sul Americano dos Estados Gerais da Psicanálise, 11, 1999, São Paulo-SP Disponível em: http:// www.estadosgenerales.org/historia/justus-alimentação.shml Acesso em: 18 novembro de 2007.

Morais, Regis. Estudos de filosofia da cultura. São Paulo: Loyola, 1992. OMS (Organização Mundial da Saúde). Carta de Ottawa. In: Buss, Paulo Marchiori (org). Promoção da Sáude e Saúde Pública. Rio de Janeiro: ENSP, 1986. 158-162. Piaget, Jean. Fazer e compreender. São Paulo: EDUSP, 1978.

Tones, Keith. Educación para la salud: prevención o subversión? In: Quadern CAPS. Tendencias actuales en educación sanitaria. n. 8, mar. Barcelona, 1987. 